JKKP : Jurnal Kesejahteraan Keluarga dan Pendidikan http://doi.org/10.21009/JKKP DOI: doi.org/10.21009/JKKP.062.05

E-ISSN : 2597-4521

\title{
DESAIN DAN IMPLEMENTASI MODEL COMPETENCY BASED-ASSESSMENT PADA PRAKTIK CLEANING BATHROOM DI HOUSEKEEPING DEPARTMENT
}

\author{
Yoyoh Jubaedah ${ }^{1, a)}$, Nenden Rani Rinekasari ${ }^{1, b)}$, dan Neni Rohaeni ${ }^{1, c)}$ \\ a)yoyohjubaedah@upi.edu, b) ${ }^{\text {nenden.rani@upi.edu, }}$ (c)nenirohaeni@upi.edu
}

1)Prodi Pendidikan Kesejahteraaan Keluarga JI Dr. Setiabudhi No. 229 Bandung 40154 Jawa BaratIndonesia, Telp.022-2013163 Fax.022-2013651, prodi-pkk@upi.edu

\begin{abstract}
ABSTRAK
Tujuan jangka panjang dari penelitianiniadalah untuk mengembangkan model competency based-assessment pada Praktik Cleaning Bathroomdi Housekeeping Department. Target khusus yang ingin dicapai dari penelitian ini adalah menghasilkan: 1) Model competency based-assessment pada pembuatan alat penilaian Praktik Cleaning Bathroom di Housekeeping Department. 2) Implementasi model competency based-assessment pada praktik Cleaning Bathroom di Housekeeping Department. 3) Capaian kompetensi pada praktik Cleaning Bathroom di Housekeeping Department. 4) Kualitas model competency based-assessment praktik Cleaning Bathroom di Housekeeping Department. Penelitian ini mengunakan metode deskriptif dengan pendekatan Research and Development. Penelitian mencakup studi pendahuluan, tahap pengembangan model, dan tahap uji validasi model. Subjek penelitian terdiri dari praktikan, penilai internal dan eksternal pada praktik Cleaning Bathroom. Teknik pengumpulan data dilakukan melalui observasi dan uji kompetensi. Analisis data penelitian dilakukan sesuai dengan prosedur dan karakteristik dari temuan data penelitian; untuk data kuantitatif dianalisis secara kuantitatif dan untuk data kualitatif dianalisis secara kualitatif. Temuan penelitian menunjukkan bahwa model competency based-assessment pada praktik Cleaning Bathroom di Housekeeping Department yang diimplementasikan memiliki keunggulan mencakup tahap persiapan, proses dan hasil sesuai Standar Operasional Prosedur Hotel. Tahapan penilaian mengacu pada Job Performance di Housekeeping Department yang diimplementasikan oleh penilai internal dan eksternalmenunjukkan capaian kompetensi praktikan sesuai standard kinerja hotel yaitu seluruhnya mencapai kompeten. Model competency based-assessment pada praktikCleaning Bathroomdi Housekeeping Department memiliki kualitas yang baikmelalui hasil uji interrater reliability dan dibuktikan dengan nilai cronbach alpha rata-rata sebesar0,854 yang berada diatas batas minimal reliabilitas 0,6 .
\end{abstract}

Kata Kunci: Desain, Implementasi, Model competency based-assessment, Cleaning Bathroom, Housekeeping Department.

\section{DESIGN AND IMPLEMENTATION OF COMPETENCY BASED-ASSESSMENT MODELS IN BATHROOM CLEANING PRACTICES IN HOUSEKEEPING DEPARTMENT}

\begin{abstract}
The long term objective of this research is to develop a model competency assessment based on the cleaning bathroom in housekeeping department. Targeted to be achieved from the study on cleaning bathroom practices in housekeeping department is to produce:(1) the competency based-assessment
\end{abstract}


model, (2) implementation of the competency based-assessmentmodel, (3) the competence result, and (4) the quality model of competency based-assessment. This research used descriptive methods with research and development approach. The research includes the preliminary study, the stage of development model, and the step of experiment validation model. The subject of this study are interns, external and internal examiner of the cleaning bathroom practices. The data collection technique was done through observation and competency test. Data analysis the research was done in accordance with the procedures and characteristic of the findings; data was analyzed both quantitatively and qualitatively. The findings showed that model competency based assessment that implemented on cleaning bathroom practices in housekeeping department have the advantages. First, it has the preparatory, proces and resultstages according to standard operating procedures hotel. Second, the assessment stage referring to job performance in housekeeping department that implemented by an internal and external appraiser, and show that of interns'competence according to standard performance hotel that is entirely reached competent. The competency based-assessment model on practices cleaning bathroom in housekeeping departmentpossed having a good qualities. It was prove through the interrater reliability test that showed the score is 0.854 more than the minimum score of 0,6 of the cronbach alpha.

Keyword: Design, Implementation, Competency based-assessment model, Cleaning bathroom, Housekeeping department.

\section{PENDAHULUAN}

Pesatnya perkembangan teknologi dan informasi saat ini berimplikasi pada berkembangnya dunia pendidikan yang harus sesuai dengan kebutuhan dunia kerja, sehingga proses pendidikan di perguruan tinggi termasuk Fakultas Pendidikan Teknologi dan Kejuruan harus Link and Matchdengan dunia kerja. Pendidikan Kesejahteraan Keluarga merupakan salah satu program studi pada rumpun pendidikan kejuruan karena lulusannya disiapkan untuk menjadi guru Sekolah Menengah Kejuruan atau SMK sesuai bidang keahlian yang dikembangkan diantaranya Akomodasi Perhotelan. Selaras dengan pendapat Finch dan Crunkilton (1984), bahwa sistem pendidikan yang dilaksanakan pada pendidikan kejuruan seyogianya mampu memberikan kesempatan kepada anak didiknya untuk membelajarkan diri dalam mengaktualisasikan semua potensi yang dimilikinya menjadi kemampuan profesional yang dapat dimanfaatkan dalam dunia kerja. Kondisi ini akan relevansi dengan tuntutan, kebutuhan, dan perkembangan dunia usaha/industri (Direktorat Pembinaan SMK, 2018).

Profil lulusan dari Program Studi Pendidikan Kesejahteraan Keluargadiantaranya harus menunjukkan kemampuan sebagai Pendidik pada jalur pendidikan formal yaitu sebagai Guru SMK Bidang Keahlian Akomodasi Perhotelan. Kompetensi tersebut dapat tercapai apabila didukung oleh layanan akademik yang mampu memberikan pengalaman belajar dalam bentuk perkuliahan dan penilaian sesuai dengan Kerangka Kualifikasi Nasional Indonesia (KKNI) yang dapat menunjukkan kemampuan kerja, sehingga lulusan memperoleh pengakuan dunia kerja (stakeholders).

Kompetensi yang harus dikuasai sebagai guru SMK Bidang Keahlian Akomodasi Perhotelan diantaranya di bidang Housekeeping Department. Unjuk kerja di Housekeeping Department meliputi penguasaan komptensi cleaning bathroom yang disiapkan untuk menjadi room attendant yang profesional, sehingga guru dituntut untuk menilai proses dan hasil praktik sesuai dengan Standar Operasional Prosedur Hotel.

Standar Operasional Prosedur adalah sekumpulan prosedur operasional standar yang digunakan sebagai pedoman dalam perusahaan untuk memastikan langkah kerja setiap anggota telah berjalan secara efektif dan konsisten, serta memenuhi standar dan sistematika (Riswano,2019).Cleaning bathroom adalah cara bagaimana roomboy membersihkan dan mengatur perlengkapan yang ada di dalam kamar mandi sehingga bersih, aman, dan nyaman (Suwithi, 2008).

Dalam implementasi pembelajaran cleaning bathroom perlu dirancang suatu penilaian tindakan (Performance assessment) yang sesuai dengan kompetensi untuk mengetahui perkembangan capaian kompetensi peserta didik, karena penilaian merupakan bagian penting dari pembelajaran (Anwar, 
Ramlawati, dan Anggraini, 2017). Alat penilaian tindakan haruslah sesuai dengan kompetensi dasar yang akan diukur dengan menyesuaikan indikator penilaian yang akan diuji dan penilaian kinerja merupakan salah satu penilaian yang disarankan dalam Kurikulum 2013 untuk mengukur ketercapaian kompetensi peserta didik, dan penilaian kinerja sangat membantu dalam penentuan keputusan melalui pengamatan dan tepat digunakan untuk menilai kompetensi peserta didik pada saat praktikum (Kunandar, 2014).

Melalui pembelajaran praktik di sekolah, peserta didik di sekolah menengah kejuruan akan memperoleh keterampilan yang sesuai dengan kompetensinya setelah mereka menyelesaikan waktu belajarnya, Seorang guru dapat menilai kinerja mereka apakah sesuai dengan Standar Operasional Prosedur yang berlaku (Rohaeni, Jubaedah, dan Rahmah, 2019, hlm. 17) pada saat praktik pembelajaran.

Pengukuran kompetensi peserta ddik di SMK khususnya keahlian Akomodasi Perhotelan melalui penerapan Model Competency Based-Assessment dengan Performance Assessment. Jubaedah dkk. (2018, hlm. 140) menyebutkan bahwa penilaian ini diarahkan untuk mengukur dan menilai performansi peserta didik dalam kemampuan kognitif, psikomotor dan afektif; baik secara langsung pada saat melakukan aktivitas belajar maupun secara tidak langsung, yaitu melalui bukti hasil belajar (evidence of learning) sesuai dengan kriteria kinerja (performance criteria).

Performance assessment merupakan penilaian yang menuntut peserta uji untuk mendemonstrasikan suatu kompetensi tertentu dengan menggunakan tes praktik, proyek, dan penilaian portofolio (Kusairi, dkk dalam Riswano, 2019). Hasil penilaian yang diperoleh dengan menggunakan instrumen penilaian kinerja lebih autentik daripada yang diperoleh dengan menggunakan tes klasik, dengan kata lain butir-butirnya lebih mencerminkan kemampuan yang diperlukan dalam praktik kehidupan sehari-hari (Agustini dan Ningtyas, 2014).

Aspek-aspek penilaian dalam pembelajaran mencakup tiga ranah (domain), yaitu ranah kognitif (cognitive domain), afektif (affective domain) dan psikomotor (psychomotor domain). Penilaian kompetensi keterampilan dilakukan dengan mengamati langsung kinerja peserta didik. Peraturan Menteri Pendidikan Kebudayaan Nomor 66 tahun 2013, tentang standar penilaian yang menyatakan bahwa pendidik menilai kompetensi keterampilan melalui penilaian kinerja (performance assessment).Komponenpenting dalam mengembangkan sistem penilaian adalah menyusun spesifikasi penilaian, meliputi: tujuan, lama penilaian dan instrumen penilaian.Instrumen penilaian tes tindakan atau praktik meliputi tahapan persiapan, proses kerja dan hasil yang telah disesuaikan dengan standar kompetensi penilaian (Jubaedah, 2009).

Cleaning bathroommerupakankompetensi pada matapelajaranproduktif, sehinggadalam proses penilaiannyaharusmenggunakanacuan kriteria (criterion-reference assesment).Inovasi sistem penilaian dengan mengembangkan competency based-assessmentpada Mata Pelajaran Produktif dapat diterapkan dalam pengembangan alat penilaian Cleaning bathroom, karena kompetensi yang harus dicapai oleh pesertadidik mencakup ketiga aspek seperti yang terpola dalam penilaian berbasis kompetensi. Dengan demikian hasil belajar pesertadidikdiharapkan mampu mencapai standar kompetensi yang telah ditetapkan dalam Mata Pelajaran Produktif dan memenuhi tuntutan stakeholders di Housekeeping Department.

\section{METODOLOGI PENELITIAN}

Pendekatan penelitian yang digunakan untuk menjawab masalah penelitian yang telah dirumuskan dalam penelitian ini adalah Research and Development (R\&D). Langkah penelitian Research and Developmentdalam penelitian ini yang disarikan dari Sukmadinata(2005)meliputi tiga tahap, yaitu : (1) Studi Pendahuluan, (2) Pengembangan Model dan (3) Uji Model (Validasi Model).

Penelitian dilakukan pada lembaga institusi pasangan tempat pelaksanaan PPL dan praktek industri bidang keilmuan dan keahlian Tata Graha, yaitu SMK Akomodasi Perhotelan dan Hotel di Kota Bandung dengan subjek penelitian terdiri dari praktikan, gurudan praktisi dari hotel sebagai penilai eksternal.Pada studi pendahuluan dipilih teknik observasiuntuk menentukan SMK dan hotel yang 
dijadikan tempat implementasi modelcompetency based-assessment pada praktikCleaning bathroomdi Housekeeping Department.

Pada tahap pengembangan model, dilakukan ujicoba instrumen penilaian Cleaning Bathroom dengan pendekatan competency based-assessment pada Housekeeping Department di SMK dan Hotel Kota Bandung sebagai institusi pasangan Program Studi Pendidikan Kesejahteraan Keluarga; meliputi ujicoba terbatas dan ujicoba lebih luassehinggamenghasilkanmodel yang siap untuk dilakukan validasi. Pada tahap validasi dilakukan implementasi modelcompetency based-assessment pada praktik Cleaning bathroomdi Housekeeping Department yang melibatkan penguji internal dan eksternal, untuk menguji keunggulan dari model yang dikembangkan melalui kajian empirik uji interrater reliability instrumen penilaian cleaning bathroom.

\section{HASIL DAN PEMBAHASAN}

\section{DesainModel Competency Based- assessment pada Praktik Cleaning Bathroomdi} Housekeeping Department

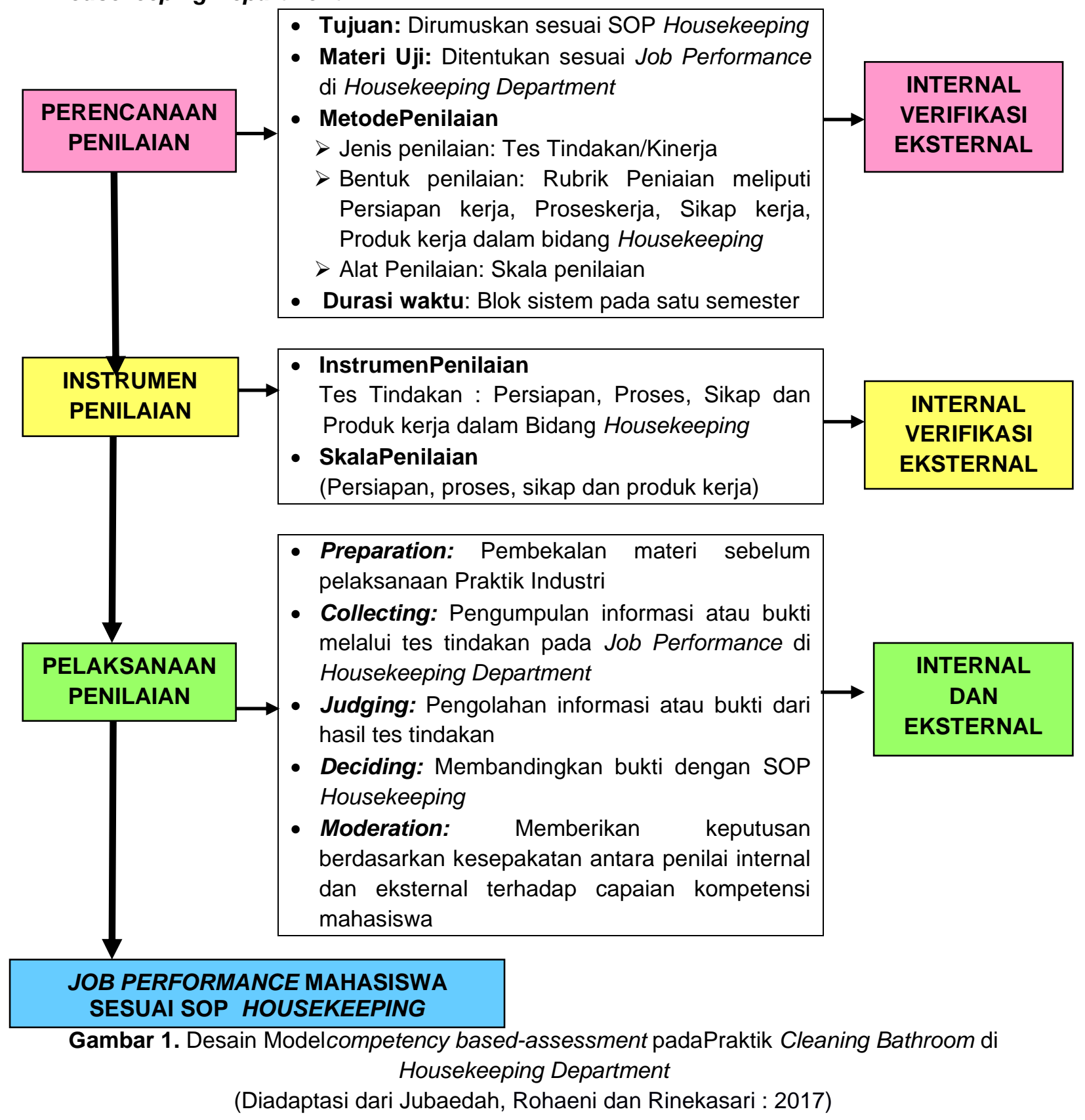


Model competency based- assessment diterapkan pada pengembangan instrumen penilaian dalam bentuk rubrik penilaian praktik Cleaning Bathroom di Housekeeping Department yang mencakup aspek penilaian sebagai berikut.

Tabel 1. Rubrik Penilaian Praktik Cleaning Bathroom

\begin{tabular}{|c|c|c|c|}
\hline No & Indikator & Sesuai & $\begin{array}{l}\text { Tidak } \\
\text { Sesuai }\end{array}$ \\
\hline A. & $\begin{array}{l}\text { Tahap Persiapan Praktik Cleaning Bathroom } \\
\text { 1. Penampilan Diri } \\
\text { a. Menggunakan seragam yang bersih dan rapi. } \\
\text { b. Berpenampilan rapi. } \\
\text { c. Bagi pria rambut pendek di atas kerah } \\
\text { d. Bagi wanita bila rambut panjang harus diikat atau di gelung. } \\
\text { e. Tidak menggunakan perhiasan dan assesories tidak berlebihan. } \\
\text { f. Bagi pria telinga tidak bertindik } \\
\text { g. Bagi wanita telinga tidak bertindik lebih dari satu } \\
\text { h. Tidak mengggunakan make-up berlebihan bagi wanita } \\
\text { i. Tidak berkumis/berjenggot bagi pria } \\
\text { j. Menjaga kebersihan tangan, gigi, kaki, badan tidak berbau, kuku } \\
\text { tidak boleh panjang. } \\
\text { k. Aroma parfume yang dipilih lembut. } \\
\text { I. Sepatu berwarna hitam dan kaos kaki bersih } \\
\text { m. Menggunakan name tag (tanda pengenal) }\end{array}$ & & \\
\hline
\end{tabular}

2. Persiapan Alat Pembersih

a. Carry caddy

b. Hand brush

c. Glass Squeegee/window wiper

d. Bottle spray

e. Dry/cleaning cloth

f. Dust cloth

g. Toilet bowl brush

h. Chamois/canebo

i. Floor squeezer

j. Mop

3. Persiapan Chemical

a. Glass cleaner

b. Floor cleaner

c. Go getter

d. Porcelain cleaner

e. Metal polish brasso

f. Air freshner

4. Persiapan Guest Supplies

a. Bath soap

b. Bath foam

c. Shampoo

d. Conditioner

e. Tissue roll

f. Matches

g. Shower cap

h. Cotton bud

i. Tooth brush and tooth paste 
j. Sewing kit

k. Sanitary bag

I. Comb

m. Bath foam

n. Shampoo

o. Conditioner

5. Persiapan linen Supplies

a. Bath towel

b. Face towel

c. Hand towel

d. Bath mat

6. Perlengkapan Pelindung Cleaning Bathroom.

a. Hand Rubber Gloves

b. Masker

c. Eye Glasses

d. Pantofel

\begin{tabular}{|c|c|}
\hline & $\begin{array}{l}\text { 7. Persiapan linen Supplies } \\
\text { a. Bath towel } \\
\text { b. Face towel } \\
\text { c. Bath mat } \\
\text { Jumlah }\end{array}$ \\
\hline B & $\begin{array}{l}\text { Tahap Proses Praktik Cleaning Bathroom } \\
\text { 1. Memasuki Kamar (OD/VD) } \\
\text { a. Menempatkan trolley cart di depan kamar yang akan dibersihkan. } \\
\text { b. Mengetuk pintu/menekan door bell tiga kali dan menyebutkan jati } \\
\text { diri "Housekeeping" } \\
\text { c. Membuka pintu kamar menggunakan master key, dan } \\
\text { mengucapkan "Excuse me". } \\
\text { d. Menyalakan lampu kamar, membuka black out curtain agar kamar } \\
\text { menjadi lebih terang. } \\
\text { e. Mengetuk pintu kamar mandi tamu apabila sudah kosong mulailah } \\
\text { untuk membersihkannya } \\
\text { f. Mengumpulkan asbak dan gelas kotor kemudian dibawa ke kamar } \\
\text { mandi untuk dicuci. } \\
\text { g. Membawa Guest Supplies dan linen ke trolley cart disimpan di } \\
\text { kantong linen kotor. }\end{array}$ \\
\hline & $\begin{array}{l}\text { 2. Cleaning Toilet Bowl } \\
\text { a. Menyiram terlebih dahulu toilet bowl dengan air dari water tank. } \\
\text { b. Menuangkan chemical ke dalam toilet bowl, lalu gosok } \\
\text { menggunakan toilet bowl brush diamkan beberapa menit. } \\
\text { c. Menggosok toilet bowl bagian dalam selesai, lalu disiram } \\
\text { menggunakan air dari water tank. } \\
\text { d. Membersihkan toilet bowl seat dan toilet bowl cover menggunakan } \\
\text { sponge dan chemical. } \\
\text { e. Membersihkan Penutup toilet bowl, tangki air dan dinding sekitar } \\
\text { toilet bowl. } \\
\text { f. Membersihkan pinggir toilet bowl menggunakan sponge dan bahan } \\
\text { chemical bilas sampai buih sabun menghilang. } \\
\text { g. Membersihkan toilet paper holder dan tissue holder. } \\
\text { cloth. }\end{array}$ \\
\hline
\end{tabular}

\section{Cleaning Bathtub}


a. Melipat Tirai plastik(Shower curtain) ke atas.

b. Menyiram area bathtub bagian dalam terlebih dahulu dengan air hangat

c. Menuangkan chemical lalu menggosok bagian dasar dinding dan tepi atas bathtub menggunakan sponge.

d. Menggosok bagian dinding sekeliling bathtub, kran air, tempat sabun, safety handle, dan safety stripe.

e. Menggosok bagian dinding dalam, luar dan bagian bawah bathtub.

f. Membersihkan tirai bak mandi menggunakan dust cloth.

g. Membilas semuanya menggunakan air dingin hingga bersih.

h. Mengeringkan seluruh bagian bathtub dan pasang kembali shower curtain .

4. Cleaning Wash Basin

a. Membersihkan gelas kotor dengan air panas lalu telungkupkan di atas wash basin table.

b. Membersihkan kaca wash basin table menggunakan chemical.

c. Membasahi wash basin table dan wash basin bowl air terlebih dahulu.

d. Menuangkan obat pembersih ke toilet bowl dan fouschet, lalu digosok menggunakan sponge.

e. Menggosok bagian luar, bawah dan saluran pembuangan wash basin.

f. Membilas dengan air untuk menghilangkan sisa obat pembersih di dalam wash basin bowl, stopper dan wash basin table.

g. Mengeringkan semua bagian wash basin menggunakan dry cloth

5. Melengkapi Guest Supplies Bathroom

a. Face towe/ 2 buah

b. Hand towel 2 buah

c. Bath towel 2 buah

d. Toilet paper 1 roll

e. Shower cap 1 buah

f. Shampoo 1 botol

g. Conditioner 1 botol

h. Bath soap 1 buah

i. Bath foam 1 buah

j. Bath mat 1 buah

k. Sewing kit 1 set

I. Tooth brush 2 buah

m. Comb 1 buah

n. Tooth paste 1 buah

6. Membersihkan dinding dan lantai bathroom

a. Membersihkan dinding dengan cara digosok menggunakan sponge dan chemical yang terlebih dahulu dibasahi air.

b. Membilas lalu keringkan dinding menggunakan dry cloth.

c. Menyiram lantai kamar mandi terlebih dahulu.

d. Tuangkan chemical lalu digosok menggunakan sponge.

e. Membilas dengan air lalu keringkan lantai menggunakan stick mop. Jumlah

C Tahap Hasil Praktik Cleaning Bathroom

\section{Final check}

a. Cleaning equipment dan chemical dikembalikan ke trolley, tidak ada yang tertinggal di kamar 
b. Kerapian guest supplies, linen supplies dalam posisi yang tepat sesuai dengan standar prosedur hotel.

c. Kebersihan tidak ada noda dimanapun

d. Mematikan lampu, jendela, menutup night curtain dalam posisi benar.

e. Mengunci kembali pintu dan menyemprotkan air freshner

\section{Waktu 15-25 menit}

Jumlah

Kriteria kinerja yang dikembangkan untuk memberikan acuan atau tolok ukur kepada penilai di dalam memberikan penilaian terhadap peserta didik secara objektif, karena penilai terdiri dari penilai internal dan eksternal yang memerlukan kesepatan di dalam menilai. Alasan lain yang lebih luas disarikan dari Arikunto dan Jabar (Jubaedah, 2009), yaitu :

1) Dengan adanya kriteria atau tolok ukur, penilai dapat lebih mantap dalam melakukan penilaian terhadap objek yang akan dinilai karena ada patokan yang diikuti.

2) Kriteria atau tolok ukur yang sudah dibuat dapat digunakan untuk menjawab atau mempertanggungjawabkan hasil penilaian yang sudah dilakukan.

3) Kriteria atau tolok ukur digunakan untuk mengekang masuknya unsur subjektif yang ada pada diri penilai.

4) Dengan adanya kriteria atau tolok ukur, maka hasil penilaian akan sama meskipun dilakukan dalam waktu yang berbeda dan dalam kondisi fisik penilai yang berbeda pula.

5) Kriteria atau tolok ukur memberikan arahan kepada penilai apabila banyaknya penilai lebih dari satu orang.

Dari alasan tersebut, maka kriteria kinerja dikembangkan mengacu pada Standar Operasional Prosedur Hotel dan dilakukan verifikasi eksternal sehingga diperoleh kriteria yang bisa dijadikan standar di dalam menilai kompetensi peserta uji, karena kriteria yang baik akan ditafsirkan sama oleh siapa saja yang menggunakannya.

2. Implementasi Model Competency Based-assessment pada Praktik Cleaning Bathroom di Housekeeping Department

a. Capaian Hasil Praktik Cleaning Bathroom Pada Tahap Persiapan

CapaianhasilpraktikCleaning Bathroom pada tahap persiapansebagian besar praktikan sudah sangat sesuai dengan indikator alat penilaian cleaning bathroom. Capaian ini menunjukkan bahwa praktikan mempersiapkan seluruh komponenen yang diperlukan dalam melaksanakan kegiatan praktik, karena pada kegiatan praktik memerlukan kondisi individu yang meliputi kematangan fisik, mental, dan pengalaman, adanya kemauan dan kemampuan untuk melaksanakan suatu pekerjaan atau kegiatan (Surokim, 2016) selain itu perlengkapan yang harus disiapkan dalam melaksanakan kegiatan pembersihan cleaning bathroom olehroom attendant yaitu mempersiapkan semua perlengkapan pembersihan seperti trolley, linen, equipment, bahan pembersih, dan aminities (Bagyono 2009).

b. Capaian Hasil Praktik Cleaning Bathroom Pada Tahap Proses

Capaian hasil praktik Cleaning Bathroom pada tahap proses lebih dari setengahnya praktikan sudah sesuai dengan indikator alat penilaian cleaning bathroom dan capaian ini sejalan dengan pernyataan Suwithi (2008) bahwa room attendent harus mempunyai wawasan yang luas, mempunyai pengetahuan dan keterampilan tentang alat pembersih, bahan pembersih serta barang-barang keperluan tamu yang ditempatkan di kamar mandi, alat-alat sanitasi, serta metode pembersihan sesuai SOP yang digunakan di berbagai hotel.

c. Capaian Hasil Praktik Cleaning Bathroom Pada Tahap Akhir

CapaianhasilpraktikCleaning Bathroompada tahap akhir sebagian besar praktikan sudahsesuai dengan indikator alat penilaian cleaning bathroom karena pada saat pelaksaanaan akhir cleaning bathroom memerlukan pemahaman tantang fungsi dan tujuan yang sesuai SOP hotel untuk 
memperlancar pekerjaan dan supaya tercapai hasil yang optimal, SOP menjadi pedoman bagi semua hotel bahwa dalam mempersiapkan atau membersihkan kamar tidur tamu hotel dan cleaning bathroom harus efisien dalam waktu dan tenaga sehingga tercapai hasil yang optimal (Perwani, 1993). Capaian ini menunjukkan bahwa praktikan sudah menerapkan disiplin waktu sesuai SOP hotel.

3. Hasil CapaianTes Kinerja Pada Praktikan

Capaian criteria tes kinerja Praktik Cleaning Bathroom seluruh praktikan sudah kompeten mencakup tahap persiapan, tahap proses dan tahapakhir. Capaian kinerja secara keseluruhan dapat dilihat pada tabel sebagai berikut.

Tabel 2. Capaian Kriteria Tes Kinerja Menggunakan Alat Penilaian Praktik Cleaning Bathroom

\begin{tabular}{|c|c|c|c|}
\hline \multirow{2}{*}{$\begin{array}{c}\text { No. } \\
\text { PesertaPraktikan }\end{array}$} & \multicolumn{2}{|c|}{ JumlahProlehanSkor } & \multirow[b]{2}{*}{ Skor Rata-rata } \\
\hline & Penilai 1 & Penilai 2 & \\
\hline 1 & 82,50 & 84,00 & 83,25 \\
\hline 2 & 85,00 & 88,00 & 86,50 \\
\hline 3 & 87,50 & 87,00 & 87,25 \\
\hline 4 & 82,50 & 82,00 & 82,25 \\
\hline 5 & 85,00 & 82,00 & 83,50 \\
\hline 6 & 87,50 & 85,00 & 86,25 \\
\hline 7 & 85,00 & 84,00 & 84,50 \\
\hline 8 & 87,50 & 85,00 & 86,25 \\
\hline 9 & 87,50 & 83,00 & 85,25 \\
\hline 10 & 82,50 & 80,00 & 81,25 \\
\hline 11 & 85,00 & 83,00 & 84,00 \\
\hline 12 & 82,50 & 83,00 & 82,75 \\
\hline 13 & 82,50 & 82,00 & 82,25 \\
\hline 14 & 80,00 & 80,00 & 80,00 \\
\hline 15 & 90,00 & 90,00 & 90,00 \\
\hline 16 & 85,00 & 80,00 & 82,50 \\
\hline 17 & 80,00 & 94,00 & 87,00 \\
\hline 18 & 82,50 & 91,00 & 86,75 \\
\hline 19 & 80,00 & 96,00 & 88,00 \\
\hline 20 & 85,00 & 81,00 & 83,00 \\
\hline 21 & 82,50 & 84,00 & 83,25 \\
\hline 22 & 85,00 & 86,00 & 85,50 \\
\hline 23 & 85,00 & 84,00 & 84,50 \\
\hline 24 & 77,50 & 76,00 & 76,75 \\
\hline 25 & 82,50 & 80,00 & 81,25 \\
\hline 26 & 85,00 & 82,00 & 83,50 \\
\hline 27 & 80,00 & 80,00 & 80,00 \\
\hline
\end{tabular}

4. Uji Realibilitas Interrater Capaian Hasil PraktikCleaning Bathroom

Uji realibilitas interrater menjadi acuan untuk mengevaluasi alat penilaian praktik cleaning bathroom menggunakan hasil dari penilai 1 dan penilai 2 dengan uji reliabilitas antar rater menggunakan SPSS dengan metode Cronbach Alpha untuk mengetahui konsistensi alat ukur, dan untuk mengetahui apakah instrumen reliabel atau tidak. Data hasil uji reliabilitas menggunakan SPSS sesuai dengan capaian tes kinerja praktik cleaning bathroom diperoleh hasil sebesar 0,854 . Nilai cronbach alpha tersebut berada di atas batas minimal reliabilitas yaitu $>0,6$ sehingga dapat ditapsirkan bahwa alat penilaian cleaning bathroom memiliki kualitas yang baik.

Hasil penelitian menunjukkan ketercapaian praktik cleaning bathroom berbasis SOP Hotel menunjukkan seluruhnya peserta didik sudah kompeten karena mencapai nilai di atas standar hotel, sehingga dapat disimpulkan praktikan pada kriteria tes kinerja sudah sesuai dengan alat penilaian dalam melaksanakan cleaning bathroom, penilaian ini menjadi acuan bagi guru untuk menentukan 
evaluasi pembelajaran dan terus meningkatkan pengembangan pembelajaran yang berorientasi kepada praktik, sebagai mana dikemukakan oleh Arikunto (2003).

\section{KESIMPULAN}

Model competency based- assessment pada praktik Cleaning Bathroom di Housekeeping Department yang diimplementasikan memiliki keunggulan mencakup tahap persiapan, proses dan akhir atau hasil karena sudah sesuai Standar Operasional Prosedur Hotel. Tahapan penilaian mengacu pada Job Performance Cleaning Bathroom di Housekeeping Departmentyang diimplementasikan oleh penilai internal dan eksternal, menunjukkan capaian kompetensi sesuai standard kinerja hotel yaitu seluruh praktikan dinyatakan kompeten. Model competency based-assessment pada praktik Cleaning Bathroom di Housekeeping Department memiliki kualitas yang baik yang dianalisis dari hasil uji interrater reliability dibuktikan dengan nilai cronbach alpha rata-rata sebesar 0,854 yang berada di atas batas minimal reliabilitas 0,6 . Hasil penelitian ini dapat menjadi rujukan pada pembekalan dan pelaksanaan Praktik Industri atau Praktik Kerja Lapangan di Housekeeping Department.

\section{DAFTAR PUSTAKA}

Agustini R dan Ningtyas K.F. (2014). Pengembangan Instrumen Penilaian Kinerja Siswa Untuk Mengakses Keterampilan Proses Dalam Praktikum Senyawa Polar dan Non Polar Kelas X SMA. UNESA Journal of Chemical Education, Vol 3 Nomor 03 . hlm 169-175.

Anwar, Ramlawati, dan Anggraini. (2017). Pengembangan Perangkat Penilaian Kinerja dan Sikap Pada Kinerja Praktikum Titrimetri dan Gravimetri SMK-SMTI Makasar. Jurnal Chemistry Education Review, Pendidikan Kimia PPs UNM, Vol 1 No 1, hlm 35-44.

Arikunto, Suharsimi. (2002). Prosedur Penelitian Suatu Pendekatan Praktik. Jakarta: Rineka Cipta.

Bagyono. (2009). ManajemenHousekeeping Hotel. Bandung: ALFABETA.

Direktorat Pembinaan SMK. Kilasan Dua Tahun Revitalisasi Sekolah Menengah KejuruanSeptember 2016-2018. Kementerian Pendidikan Dan Kebudayaan, ISBN: 978 - 602 - 5517 - 36- 5

Finch, C. dan Crunkilton, J.R. (1984). Curriculum Development in Vocational and Technical Education: Planning, Content and Implementation. Boston : Allyn and Bacon, Inc.

Jubaedah, Y. dkk. (2018). Model Competency Based-Assessment pada Pengembangan Job Performance Public Area di Housekeeping Department. Jurnal Kesejahteraan Keluarga dan Pendidikan [JKKP] Vol.05 No.02. 139-146..

Jubaedah,Y., Rohaeni, N., dan Rinekasari, N.R. (2017). Development Of Competency Based Assessment Model on Job Performnace In Family Welfare Education Apprenticeship. Jurnal Inovasi pendidikan Kejuruan Teknologi. Vol XIII,

Jubaedah, Y. (2009). Model Penelitian Keahlian Tata Busana Berbasis Standar Kompetensi Nasional di Sekolah Menengah Kejuruan Program Studi Pengembangan Kurikulum Sekolah Pascasarjana Universitas Pendidikan Indonesia. Disertasi. Universitas Pendidikan Indonesia. Bandung

Kunandar. (2014). Penilaian Autentik, Penilaian Hasil Belajar Peserta Didik Berdasarkan Kurikulum 2013. Jakarta: Rajawali.

Perwani, S.Y. (1993). Teori dan Petunjuk Praktik Housekeeping untuk Akademi Perhotelan : Make Up Room. Jakarta: PT. Gramedia Pustaka Utama.

Riswano. (2019). Implementasi Alat Penilaian Praktik Cleaning Bathroom Berbasis Standar Operasional Prosedur Hotel di SMKN 15 Bandung. Program Studi Pendidikan Kesejahteraan Keluarga, Departemen Pendidikan Kesejahteraan Keluarga, Fakultas Pendidikan Teknologi dan Kejuruan, Universitas Pendidikan Indonesia.

Rohaeni, N., Jubaedah, Y, dan Rahman, A.A. (2019). Competency Based Assessment pada Perancangan Alat Penilaian Kinerja Praktik Making Bed di Housekeeping Department. Jurnal Kesejahteraan Keluarga dan Pendidikan [JKKP] Vol.06 No.01.

Sukmadinata, N.S. (2005). Metode Penelitian Pendidikan. Bandung : PT Remaja Rosdakarya. 
Surokim. (2016). Pengaruh pengalaman Praktek Kerja Lapangan dan Kepercayaan Diri Terhadap Kesiapan Kerja Siswa SMA Negeri 15 Semarang. Jurnal Psikoborne. 4, 566.

Suwithi, Ni Wayan. (2008). Akomodasi Perhotelan. Hotel dan Departemen. Klaten: Direktorat Pembinaan Sekolah Kejuruan. 